\title{
THE VALUE OF HOSPITALS FOR SCARLET FEVER.*
}

\author{
By W. G. WILLOCGHBY, M.D., \\ Medical Officer of Health, Eastbourne.
}

IT is notorious that hospitals for the isolation of cases of Scarlet Fever have recently received a very large amount of adverse criticism from various quarters, and the alleged objections to them have been so forcibly urged, that it is incumbent on every Medical Officer of Health to search out for himself whether in his particular district the hospital isolation of scarlet fever has proved useful or not, and if not, to study the reasons for the failure.

Large quantities of statistics have been compiled by those who feel that the isolation of scarlet fever in hospitals is either harmful or at least is not worth the expense, and having examined the figures of my own district (which show the contrary), I think the experience of what is probably the best town as regards scarlet fever isolation in the country, although it is but a small borough of about 45,000 inhabitants, may be of interest.

It is an elementary fact in statistics that the smaller the figures the less accurate the result is likely to be, and mine are so small that I only produce them for what they are worth, and do not pretend to make any general deductions from them; but an advantage of the experience of a small district, such as Eastbourne, is that the very smallness of the total number enables one to have a personal knowledge of the cases, including both those that stay at home and those that are removed to hospital.

I think I am quoting Dr. Newsholme in saying that although it is said that statistics can be made to prove anything, nothing can be proved without them, and therefore it is impossible to do without statistics. It seems to me, however, after studying the figures of other towns and of my own, that statistics in the instance of scarlet fever hospitals are most misleading, and are apt sometimes through unavoidable errors to prove too much.

In my enquiry I have found how impossible it is on this subject to get sufficiently accurate figures to build up tables warranting dogmatic conclusions, and I am also of opinion that the advantage or not of isolation of cases of scarlet fever in a fever hospital is really a subject for local enquiry rather than general, for some objectors certainly

* Read at a Meeting of the Southern Branch of the Incorporated Society of Medical Officers of Health, Portsmouth, January 18, 1905. 
seem to prove their case to some extent; and that it is for each one managing such an institution, and for the Medical Officer of Health, if the two are not combined in one office, to judge whether his locality is benefiting or not by his particular hospital.

There is no question that these hospitals are expensive, and that their up-keep is also expensive; some of these hospitals have been built in a way that is unnecessarily expensive. In my own town the total cost to the ratepayers of the isolation hospitals (including disinfection) for the past five years has averaged £1576, which is equivalent to a rate of a little over Id. in the pound, and I unhesitatingly say the ratepayers have excellent value for their money. In these remarks I omit any reference to the advantages any sick child derives from removal to proper nursing, diet, etc., from an unhealthy home, since I am dealing with hospitals for scarlet fever as they affect the community, rather than the individual.

The allegations against scarlet fever hospitals may be classified under three heads :-

1. That the hospital is useless as a means of preventing the occurrence of cases and fatal results from the same, i.e. that there has been no reduction of incidence and no reduction of scarlet fever death-rate from their use, even if the reverse is not the fact.

2. That the hospitals are dangerous in themselves to eases sent there, principally through the aggregation causing complications that might not occur elsewhere.

3. That the hospitals cause return cases. (This should be put "That return cases occur after discharge of cases from hospital.")

I propose to take these allegations seriatim.

First, with regard to the hospital being useless as to the prevention of cases. In this respect the figures obtained by Dr. Waddy, of Sheffield, and which at the Glasgow Meeting of the Congress of the Sanitary Institute, July, 1904, were backed up as being very accurate by the present and by the late Medical Officers of Sheffield, are most striking.

After carefully eliminating by statistical tables all the various causes which would in his opinion tend to explain away the figures, Dr. Waddy has come to the remarkable result in his statistics that, even taking into account all the untoward circumstances, the secondary incidence of scarlet fever has fallen worse on houses where patients have been removed to hospital, than where the patients were kept at home, and that hence the hospital is useless or worse than useless in respect of the occurrence of secondary cases; in fact, following the argument out to its logical conclusion, he has apparently proved by his figures that to keep a patient with scarlet fever in the house is 
safer for the remaining inmates of the house than to remove the primary case to hospital. This is what I mean by statistics proving too much. If the accuracy of the figures is accepted (and they were most carefully obtained) and if they are sufficient upon which to base deductions, it pays the Sheffield householder, if a case of scarlet fever occurs in his house, to keep the case at home, as thereby ipso facto secondary cases are less likely to occur. There is obviously a fallacy somewhere, notwithstanding Dr. Waddy's care ; for it must be absurd to say that while all other things are equal there is less chance of a secondary case if the first is kept in the house, unless it is all chance. or scarlet fever is a non-infectious disease. The fallacy is, I think that one cannot possibly get sufficient data tabulated to eliminate chance of error.

I daresay in most places it will be found on examining the figures that there are as many, if not more, secondary cases occurring in houses where the first cases have been removed to hospital, than where the cases have been kept at home (I grant this, although in Eastbourne my experience is quite the reverse, the percentage of secondary cases to number of children exposed in hospital cases having been in 10 years 11.9 per cent, and in home cases 71.4 per cent). But statistics in this respect are most misleading from the fact that it is impossible fairly to compare the cases by such statistical tables. Amongst those classified as "kept at home," are doubtful cases, and cases which have been notified and are found not to be cases. Genuine cases which are kept at home are those in the houses of the rich and well-to-do, or where the child is the only child in the house. In fact, those not removed to hospital are just the cases from whence spread could scarcely come, for the above and other reasons.

I know attempts have been made to construct tables eliminating some of these items, but it is impossible to properly eliminate all, especially the doubtful cases and mistakes in diagnosis. In the last ten years the cases of scarlet fever in Eastbourne were 691, and 47 of these were not removed to hospital. Since $1900 \mathrm{I}$ have personally investigated all cases of non-removal, viz. 17 , and having a personal knowledge of them all I can give the reasons for non-removal, as follows :-

In 1900, two cases were not removed out of 51. One was a doubtful case which turned out to be German measles, and one was the delicate baby of very rich parents, and there was no other child in the house. How could secondary cases arise from these?

In the next year, out of 106 cases 5 were not removed. In one of the five cases the disease was said to be a second attack in a former patient, very doubtful I should sav; the second case was that of an 
adult with no children in the house; the third case was that of an infant of 4 months; the fourth was an ordinary case; and the fifth case was notified in a late stage in a high-class house, where the rent would be at any rate over $£ 200$ a year, and the isolation accordingly good.

In 1902, out of 102 cases 7 were not removed. One of these was that of an invalid only child with no other child in the house, and this was followed by a secondary case in an adult after recovery of the first case; the second case was a doubtful case kept under observation at home; the third and fourth cases were those of two sisters who were brought from London suffering from the disease, and these caused one if not two other cases in other houses through the attendant, although they were isolated as carefully as possible in a house with no one but a nurse; the fifth was an ordinary case; the sixth was a case which, although notified, was noticed to be out and about perfectly well within four weeks, and was probably not a case; and the seventh was a child in the house of its own medical man, and accordingly under special arrangements for isolation. The fifth case, which was an ordinary case kept at home, caused indirectly the occurrence of three other cases.

In 1903, three cases of those notified were kept at home. One was in a house rented at over $£ 100$ a year, and the other two were in one family and were notified by one doctor, although two other doctors contradicted the diagnosis.

Of these 17 cases kept at home, one-fifth were not scarlet fever at all! How could statistics be built up on such a foundation? And this example of vagueness of home cases in a small town, where the individual cases are known to the Medical Officer, is probably but a sample of what takes place in other towns where it is not possible, owing to numbers, to have such personal knowledge of the cases, and where statistics are built up such as those of Sheffield. In the few instances where these home cases could cause secondary cases in the same houses, they generally did so, but as a rule it was not possible.

Now to take a converse example of the uselessness of these statistics.

In one family in Eastbourne, in June last, six children on closely succeeding dates were removed to hospital. This according to similar statistics, would be included in the tables showing that the removal of the primary case to the hospital had failed to stop the spread of the disease in the family. But on careful investigation, later on, it was found that a child kept at home was the original cause of all these cases, and therefore the hospital did not and could not in such a case have a chance to do anything towards stopping the spread, and it was really an occasion of a home case causing 6 others. If the illness 
of the original child had not been suppressed by the parent when inquiries were made by the inspector, and the child had been removed to the hospital, in all probability four or five of the succeeding six cases would have been averted, for the original child was ill a fortnight before the first of the others were attacked.

Case after case of this sort, slightly varying in detail, can be found by personal investigation, and I contend therefore that figures showing the cases that occur in a house after a child has been removed or after a child has been kept at home, really cannot, owing to want of data, be used in any fairness to show whether the hospital is acting well or not.

The cases that are taken to hospital as a rule in large towns, or indeed anywhere, are those whose diagnosis is more certain, where there are many children in the family, where the people are poor, the houses more dilapidated, and where disinfection is likely to be the more incomplete from various difficulties, and where the people are not sufficiently educated to prevent them hiding away some of the patients' clothes to avoid disinfection, for fear of spoiling, in fact just where the opportunity and pabulum for secondary cases most exist.

In a table I had prepared showing the average number of children per house and the average rent in home cases as compared with those cases removed to the hospital, I was astonished to find that in one year, while the average number of children in the houses was 4.5 in the home cases, it was but 2.5 in the cases of children removed to the hospital, and yet in the home instances no secondary cases occurred. This in a way illustrates the uselessness of statistics for small figures, and the liability to error in large figures; for on ascertaining the actual facts I found there were only two cases kept at home that year, and one of these, although notified as scarlet fever, was not a case of scarlet fever at all, and the other was the infant child of rich parents (the father a M.P.) whose other children were grown up.

It might be said that if isolation hospitals for scarlet fever are of any use, and the cases at Eastbourne are so particularly well isolated, why do cases occur at all? Up to date this year 1904 (Sept.), 26 cases of scarlet fever have been notified in Eastbourne, of which one only was kept at home (I personally visited this case, and the medical attendant agreed with me that it was really not a case ; if it had been. the parents would have consented to removal to hospital).

The causes of the remaining 25 cases in Eastbourne were as follows: Four cases were imported from London or the neighbourhood; seven cases occurred in one school on the probable introduction from outside; nine cases were traced to an unsuspected case at a crèche; one of the 
remaining five was an assistant at a place where visitors were constantly coming, and four were not traced.

There were therefore apparently only seven original cases in a population of 45,000 or more, during the first nine months of 1904 . $I$ have taken this instance simply because the facts are more recent.

It is impossible to have a great reduction of incidence while the intercourse between towns is so constant and so great. While there is only partial isolation in most places the system is not given a fair test, but it is fair to assume that by taking one's eases at once into hospital, one prevents their causing spread in other districts, and if isolation in hospitals were complete, then the incidence of the disease could be affected. The missing of the very mild cases would, however, always permit the occurrence of a certain number.

As regards the incidence of scarlet fever in Eastbourne, and the general number of children attacked: The average number of births in Eastbourne for the past ten years has been 917 annually, while the average mortality of infants has been 112 per 1,000 births. This leaves 805 children yearly, of which a few per annum would die just after infancy, leaving approximately 800 children annually who are liable to be attacked with scarlet fever.

The average number of cases of scarlet fever for the past ten years has been 69 , which if all were local children, shows that $8 \frac{1}{2}$ per cent of the children are attacked with scarlet fever; but less really are attacked because some of the cases were in adults or visitors.

Thus at least $91 \frac{1}{2}$ per cent of the children of Eastbourne eseape scarlet fever, which I am sure would not be the case were we not to take to hospital the cases which are thrust in on us from time to time. Owing to the large number of schools, there are very many extra children in Eastbourne of "scarlet fever age."

In 1903 the scarlet fever incidence for England and Wales was 1 in 427 , in Eastbourne it was 1 in 1034. The death percentage of England and.Wales for scarlet fever to cases notified was 3.4 per cent, for Eastbourne nil. 1903 has been taken because it is the last published year of the L.G.B. reports.

It is also said that there is no reduction of the death-rate from scarlet fever generally, and that the hospital is therefore useless; but this is not the experience of Eastbourne.

From 90 per cent to 100 per cent of the cases that occur in Eastbourne are isolated in the hospital, and there have been seven deaths from this disease in ten years, 1894-1903, while there have been notified 691 cases, a fatality of almost exactly 1 per cent. This is a small death-rate from a disease where serious complications are liable to occur. One of these seven deaths was that of a patient who was not 
removed to the hospital. As regards the other six deaths, one was admitted dying with another disease, one was ill with the effects of measles when admitted with scarlet fever, one died of whooping cough, two died of albuminuria and its accompanying complications, and one died from the intensity of the disease in the early stage.

Secondly, it is alleged that the hospital is dangerous to the case sent in, that the aggregation of cases leads to complications, and that the patient has a worse chance if sent to the hospital. This I consider to be a matter for local enquiry, and if any particular hospital is dangerous to the cases from aggregation, then it is time that the hospital is reformed; it is not a cause for condemning hospitals as a whole.

The experience again of Eastbourne, where one has a personal knowledge of the cases, is that of the 644 cases admitted in the ten years, six died, i.e. less than 1 per cent; of the 47 cases kept at home one died, i.e. just over 2 per cent, although the cases of mistaken diagnosis, doubtful and mild cases, and children of the well-to-do, are included among these 47 who were kept at home. I grant that these figures are too small on which to dogmatize, but in speaking of this subject generally I have been challenged to produce the figures.

As regards fatality, therefore, we have nothing for which to blame the hospital, but rather the reverse. A hospital mortality of less than 1 per cent for scarlet fever can be obtained, if the hospital is properly equipped and managed.

As regards complications, in the ten years during which 644 cases have passed through my hands, I have not seen a case of postscarlatinal diphtheria; I have but on one occasion seen children suffer from another disease, and that was when five caught measles from a case that was sent in under a mistaken diagnosis; they all recovered, and were none the worse for the mishap; there have been but five cases of renal complications, and one of the fatal cases had an attack of renal disease before admission. I have had two bad cases of pleurisy and one of pericarditis in the 644 cases; I have had to open abscesses for three or four only, and have had to operate for abscess over the mastoid in one case; all these recovered, apparently none the worse for the trouble, with one exception, a patient who had permanent after-effects from abscess in the ankle joint.

If scarlet fever hospitals are, as has been alleged, not only no good, but even harmful, Eastbourne ought to suffer terribly because of its high percentage of removals, but I think I have shown that not only the incidence rate and the death-rate, but also the proportion of cases which have complications are very small. But even if in a hospital the complications and death-rates are worse than for cases outside, is it not natural ? 
The cases not admitted are the doubtful, the very mild, and the children of the rich, well nourished and well prepared to stand an illness.

On the other hand the eases admitted are those from poor, unhealthy, and often overcrowded houses; the children are ill nourished and not prepared to stand an illness. They have the actual complications on admission very frequently.

It would be unnatural in my opinion in a large city, if the scarlet fever hospital did not sometimes show a higher complication and death-rate, for the reason that the hospital gets the worst cases.

The third allegation against scarlet fever hospitals is that return cases are caused, and that the hospital is therefore harmful.

It is unfortunately true that, after eliminating cases where the return is but a coincidence, and after excluding instances such as the taking out of clothes that were not properly disinfected, etc., hospitals cause return cases. I am of opinion that return cases arise from two causes : firstly, error of management of discharge, and secondly persistence of infection in certain cases, which persistence would be the fact whether the patient went to the hospital or stayed at home.

As regards the Eastbourne Hospital and return cases, of the ten years under review, in five years there were no return cases; in fact, the cases occurred in batches, and particularly in the year 1901. In the ten years there have been altogether 31 cases which might be classed as return cases. Of these 12 occurred just about one period, viz. at the end of September and October, 1901, and caused considerable disquietude. The other cases had occurred at varying intervals during the five previous years, as follows: in 1896 four cases; in 1897 five; in 1898 two; in 1899 one; in 1900 two.

Although there have been 31 return cases, there have been only 22 real instances, for nine cases were secondary to the return cases.

After the last batch of 1901, although no special difference was made, a considerable commotion was set up concerning these cases and the slur it would bring on the hospital if this continued; it is a striking fact that there have been no return cases since, i.e. the last occurred in 1901.

This is not the time to go into the methods employed to prevent return cases, and beyond separating the convalescents and having a special scarlet fever discharge block and a steam disinfector on the spot, there are but few special means taken to prevent return cases, although we have not had any for three years; each individual, however, who is concerned with the disinfecting has been assured that his or her duty must be thoroughly performed.

On the whole question, although my own figures are so favourable 
to hospitals, I think that statistics must only supplement the actual experience of the Medical Officer in eharge of the district. It is absolutely necessary for him to get out his statistics, but the more he attempts to do so the more hopeless he will find it to make a fair set of tables showing how hospitals affect the incidence, etc., of scarlet fever.

The great blot at present on hospitals is " return cases," and every effort should be made to stop the occurrence of these; but there is a limit to the stopping of these owing to long persistence in certain cases.

If a hospital is dangerous to cases, in that it gives rise to complications and has a very high death-rate, then it is time that that hospital is reorganized as to its accommodation, management, etc. But it must not be assumed, because a hospital has a higher death-rate for scarlet fever than the death-rate for those cases remaining outside, that the hospital itself is an evil. If the doubtful and the mild cases and the children of the well-to-do were admitted, and the cases under opposite conditions excluded, then you would soon make a very high death-rate outside, and a very low death-rate in hospital.

I do not submit my figures as those on which should be based any general deductions whatever, for two reasons : in the first place any available statistics anywhere on this subject cannot from their necessary imperfections give us accurate summaries of the facts, but if properly used can only lead us to their more complete examination; and secondly, my figures are of course too small. The cases and figures in Eastbourne, however, bear out what one knew from general experience, viz. that the hospital gets the worst, the complicated, and the undoubted cases, and therefore in a general way would be bound to suffer most ; that in spite of this its cases do as well, if not better, than those outside; that where the primary cases were removed to the hospital, fewer secondary cases occurred; and that the total incidence of, and death-rate from, scarlet fever in Eastbourne, where isolation is so thoroughly carried out, is proportionately very small.

\section{DISCUSSION.}

Dr. Groves remembered when scarlet fever was of a virulent type, and thought that it was likely to take on such a type again, when it would be a more serious disease to deal with than it is now.

Dr. Lockhart Stephens looked upon all cases of scarlet fever as serious; and deprecated the use of the term "mild" for certain cases. He gave his experience in the treatment of cases, which originated some consideration of these points.

DR. LAUDER gave some account of his methods. The patients were only kept in bed for two days after the temperature was normal, and were discharged in four weeks or less. If there was any nasal discharge he operated under an anæsthetic and removed the adenoids or tonsils with uniformly good results. 
Dr. Fraser, in discussing some of the points in Dr. Willoughby's paper, said he would first congratulate him on his courage in taking up the cudgels on behalf of the practice of the hospital isolation of scarlet fever, which apparently few Medical Officers of Health of large towns care to do. He had looked forward to his paper with considerable interest, and though he did not expect he would be able to present a very strong case in favour of the isolation hospital, he confessed he did not anticipate that he would give us such ample confirmation as he has done of the faults of the system.

Dr. Willoughby based his opinions on the facts as they have occurred in Eastbourne, yet he rather disarms criticism by acknowledging that the figures he has presented, and the town of Eastbourne, are too small to afford reliable data. With this the speaker agreed. Another point is that Eastbourne is a rich residential town, without a large population of poor, and without those large elementary schools which every Medical Officer of Health of a large town finds are the most potent agents in spreading scarlet fever. And if there is excessive freedom from scarlet fever in Eastbourne, one is more likely to be correct in attributing it not so much to the isolation hospital as to the well-to-do character of its inhabitants. But is Eastbourne really particularly free from scarlet fever, taking into consideration the character of the town and its residents? It seemed to him that Dr. Willoughby's paper would have been more valuable if he could have given the scarlet fever attack-rates in one or two similarsized towns to Eastbourne that have not adopted the isolation hospital. and could have shown that by comparison Eastbourne enjoyed a greater immunity from scarlet fever than these. This, however, he has not done, and there is nothing to indicate that the large isolation hospital expenditure mentioned has given Eastbourne any advantage over other towns in this respect.

One of the points made by opponents of isolation hospitals is that the errors of diagnosis in cases of scarlet fever frequently cause persons who have not got scarlet fever to be taken to hospital, where they naturally soon contract the disease. Dr. Fraser had not expected to find so much confirmation from Dr. Willoughby on this point, but he tells us that 6 out of 17 , or 34 per cent, of the cases of scarlet fever treated at home had been wrongly diagnosed; now if there has been the same percentage of error in Eastbourne in the cases admitted to hospital as amongst those treated at home, it will be seen that over 100 of the 644 cases sent to the Eastbourne Isolation Hospital had not really got scarlet fever at all! Again, in dealing with return cases, Dr. Willoughby does not make out a very strong case for the isolation hospital. During ten years he has had 31 return cases caused by 22 discharges, or 5 per cent returns on his discharges, and in 1901 the return cases ran up to 12 per cent. This only substantiates his (the speaker's) contention that, no matter how good the management is, it is impossible to say when infection is over, and there is confirmation in Dr. Willoughby's own words : "Return cases depend on two causes-error in management of discharge; and, secondly, persistence of infection in certain cases." Exactly, persistence of infection in certain cases; nobody knows how long it persists, but it is known to have persisted and caused a return case after eight months' detention in hospital. No opponent of the isolation hospital could expect to obtain greater confirmation of their views than is afforded by these two admissions of Dr. Willoughby.

We must certainly congratulate Dr. Willoughby on the very low death-rate from scarlet fever in his hospital; a death-rate of 1 per cent, 
although it indicates a very mild type of the disease, indicates at the sume time that the management of the hospital and the care and attention bestowed on the patients is of high order. Also, it must be most satisfactory to him to find that he has never had a case of postscarlatinal diphtheria; unfortunately, in view of the fact that this disease undoubtedly occurs in from 2 to 3 per cent of the cases of the majority of hospitals in the kingdom, the fact of its absence in Eastbourne cannot convey much weight in supporting the practice of the hospital isolation of scarlet fever.

In conclusion, Dr. Willoughby's paper might be summarized as follows :-

We have in Eastbourne a specially-selected residential health resort, without a large poor population, with proportionately a very large staff of sanitary inspectors (1 per 11,000 population), with an expensive isolation hospital, with 90 per cent of the cases of scarlet fever isolated, and yet there are still seventy cases of scarlet fever per year. One word as to the expense. Dr. Willoughby has stated that the results of the isolation hospital are well worth the money expended on it. He tells us that the annual cost during the past ten years has been $£ 1,576$. Suppose half of this sum be taken as representing the cost of the scarlet fever patients, probably far too low an estimate, we find that scarlet fever, an exceptionally mild disease which he admits only has a case death-rate of only 2 per cent if treated at home, has cost the inhabitants of Eastbourne no less than $£ 11$ per case !

With reference to Dr. Groves' remarks that he could not support the doing away with isolation hospitals, because scarlet fever was a disease the virulence of which varied at different periods, and that although scarlet fever was mild now, a time might come when it will be very virulent again, I submit this has really nothing to do with the question under discussion. If isolation hospitals do not control mild scarlet fever there is no reason whatever why it should control scarlet fever when it develops a virulent form.

DR. WILLOUghBY, in reply, remarked that he was glad of Dr. Fraser's criticisms. He said that Eastbourne was not favourably placed as regards scarlet fever, there were so many schools for children of "scarlet fever age"; if his cases in hospital had any complications, it was as a rule because they had them on admission. Dr. Fraser was wrong in thinking that cases of wrong diagnosis got into the hospital: that was seldom the fact, because if the medical man notifying had a doubt he kept them out, and yet they were still called "scarlet fever," and of course secondary cases could hardly arise. Again and again, when cases of scarlet fever arose in Eastbourne, it was due to importations from places where isolation was not carried out, and therefore Eastbourne with its good isolation could not help that.

Carbon Dioxide alleget to be the Cause of Beri-beri.-Albert S. Ashmead, of New York, presents evidence in the Sei-I-Kwai, of Tokio, to show that the charcoal braziers, used all the year around in Japanese houses, are the cause of beri-beri. They generate carbon dioxide, which is the more injurious from the custom of sleeping on the floor. The Chinese have beri-beri when they burn charcoal, but when they burn other fuel there is no beri-beri. He regards ozonization as the proper treatment. 